\title{
CULTIVO DE PHYSALIS ANGULATA L. SOB DIFERENTES DOSES DE ADUBO E SUA INFLUÊNCIA NO PESO DE SEMENTES.
}

\section{Josandra Souza Teles Fonseca ${ }^{1}$; Claudinéia Regina Pelacani ${ }^{2}$; Natália dos Santos Barroso $^{3}$ e Cristiane Amaral da Silva Ramos ${ }^{3}$}

\footnotetext{
1. Bolsista PIBIC/CNPq, Graduando em Agronomia, UEFS, e-mail: josandrateles@ hotmail.com

2. Orientador, Departamento de Ciências Biológicas, UEFS, e-mail: claudineiapelacani@gmail.com

3. Discente do Programa de Pós-Graduação em Recursos Genéticos Vegetais, UEFS, e-mail: nataliasbarroso@yahoo.com.br; crisamaral26@hotmail.com
}

PALAVRAS-CHAVE: Solanaceae; adubação química; peso de sementes.

\section{INTRODUÇÃO}

Mesmo com promissor potencial para a produção de fármacos ou ainda na fruticultura, por apresentar frutos comestíveis, pouco se sabe acerca das técnicas e manejo adequados para o cultivo da espécie Physalis angulata L. Quanto aos requerimentos nutricionais, os estudos até agora apontam uma necessidade de fornecimento externo de matéria orgânica e nutrientes, acelerando não apenas o crescimento, mas também afetando o ciclo fenológico das plantas e produção de flores e frutos (CRUZ et al., 2015; LEITE et al., 2017). Ainda não estão bem definidas quais as fontes de nutrientes e as dosagens dos macronutrientes mais efetivas. Nesse sentido, adequações das condições de cultivo se fazem necessárias a fim de se obter material de melhor qualidade e que deverão ser refletidas na qualidade dos frutos e sementes produzidos. Em termos comerciais, ou mesmo experimentais, há necessidade de apropriar todos os processos dirigidos à obtenção de sementes sadias e vigorosas visando a conservação das espécies bem como no fornecimento de germoplasmas para plantios.

Assim, este trabalho objetiva cultivar plantas de $P$. angulata em ambiente protegido e avaliar a influência de dosagens de adubação química no desenvolvimento dos frutos e no ganho de peso de sementes.

\section{MATERIAL E MÉTODOS}

Frutos de Physalis angulata foram produzidos em ambiente protegido (viveiro tipo telado) no período de setembro a novembro de 2017 no Horto Florestal da Universidade Estadual de Feira de Santana. As devidas proporções nutricionais foram estabelecidas a partir da análise físico-química e da recomendação para a cultura do tomateiro (Solanaceae). Foram utilizados como fontes de macronutrientes a uréia $(\mathrm{N})$, super simples $(\mathrm{P})$ e cloreto de potássio $(\mathrm{K})$, aplicados dois terços (2/3) no transplantio e um terço (1/3) 15 dias após o transplante. Foram testadas as seguintes dosagens: (1) solo sem correção; (2) solo com correção contendo $25 \%$, (3) $50 \%$, e (4) $100 \%$ dos macronutrientes recomendados. $\mathrm{O}$ experimento foi conduzido no esquema de blocos ao acaso ( 3 blocos x 4 dosagens). Cada parcela era representada por 5 plantas.

Ao final do cultivo (65 dias após o transplantio) foram feitas as medições de altura $(\mathrm{cm})$, diâmetro do colo $(\mathrm{mm})$ e número de frutos nas plantas de Physalis angulata. Em seguida os frutos foram colhidos, levados ao laboratório e separados pela coloração do tegumento externo de acordo com a cartela de cores RHS, representando 
os estádios de maturação (E1- verde escuro, E2- verde escuro+roxo amarronzado, E3E5- marrom amarelado claro+roxo amarronzado). Nos dez frutos por tratamento foram feitas as seguintes medições: comprimento e diâmetro $(\mathrm{mm})$, massa de matéria fresca (g) e o peso de 50 sementes secas $(\mathrm{g})$. Os resultados obtidos foram analisados quanto à normalidade e homogeneidade e quando atendido aos pressupostos foi realizada análise de variância (ANOVA). A diferença entre as médias dos dados biométricos das plantas e caracterização dos frutos foram comparadas pelo teste Tukey, 5\% de probabilidade, e o número de frutos e peso de sementes, comparados por regressão utilizando o programa computacional SISVAR-2010.

\section{RESULTADOS E DISCUSSÃO}

A maior disponibilidade de $\mathrm{N}, \mathrm{P}$ e $\mathrm{K}$ no solo contribuiu para as maiores médias de altura $(49,15 \mathrm{~cm})$ e diâmetro do colo $(10,49 \mathrm{~mm})$ de plantas de $P$. angulata (Tab. 1$)$. Esse resultado era esperado visto que os macronutrientes são constituintes das principais estruturas das plantas e quando em quantidades suficientes proporcionam o crescimento da planta e como observado, também, na figura 1, proporcionou maior média do número de frutos $(37,53)$ por planta. Os resultados corroboram ao obtido por Lima et al. (2009) em trabalho realizado com $P$. peruviana, no qual obtiveram maior altura e maior diâmetro do ramo principal com a aplicação de adubação igual ou superior a recomendada para a cultura de tomate.

Tabela 1. Altura de plantas e diâmetro do colo de $P$. angulata submetidas à diferentes dosagens de N, P e K.

\begin{tabular}{ccc}
\hline Tratamentos & Altura (cm) & $\begin{array}{c}\text { Diâmetro do colo } \\
(\mathbf{m m})\end{array}$ \\
\hline $\mathbf{1}$ & $27,82 \mathrm{~b}$ & $5,60 \mathrm{~b}$ \\
$\mathbf{2}$ & $36,87 \mathrm{ab}$ & $7,24 \mathrm{ab}$ \\
$\mathbf{3}$ & $42,26 \mathrm{ab}$ & $8,33 \mathrm{ab}$ \\
$\mathbf{4}$ & $49,15 \mathrm{a}$ & $10,49 \mathrm{a}$ \\
\hline
\end{tabular}

Médias seguidas das mesmas letras não diferem entre si pelo teste Tukey ao nível de $5 \%$ de probabilidade. Tratamentos: $1=$ controle; $2=25 \% ; 3=50 \%$ e $4=100 \%$ da adubação recomendada.

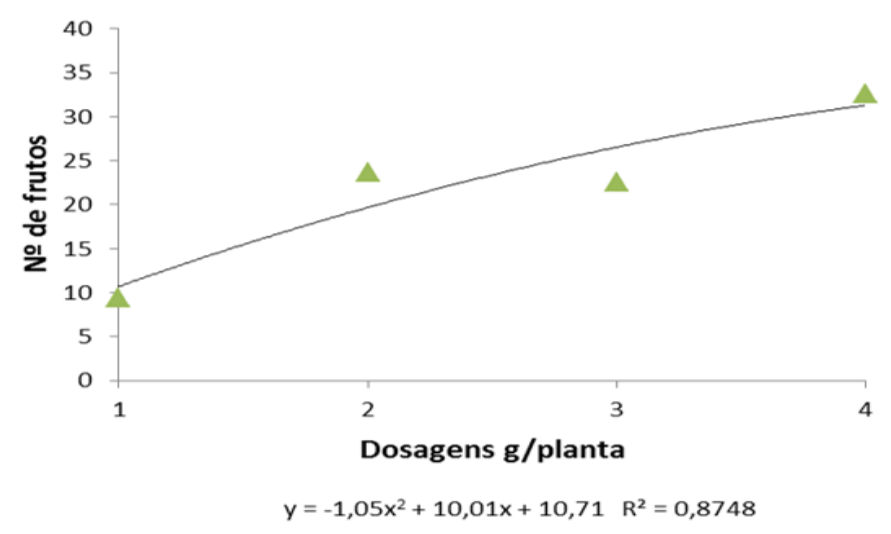

Figura 1. $\mathrm{N}^{\mathrm{o}}$ de frutos por plantas de $P$. angulata submetidas à diferentes dosagens de $\mathrm{N}, \mathrm{P}$ e K. Dosagens: 1 - controle; $2-25 \% ; 3-50 \%$ e $4-100 \%$ da adubação recomendada para o tomate. 
Como evidenciado, o fornecimento exógeno de $\mathrm{N}, \mathrm{P}$ e $\mathrm{K}$ em dosagens apropriadas, exerceu influência no incremento das médias de crescimento das plantas de $P$. angulata mas não mostrou interação significativa para os diferentes estádios de maturação dos frutos, exceto no E5 quando foi utilizado as maiores doses nutricionais. Entre os estádios de maturação dos frutos, verificou-se que o estádio E4 foi aquele que apresentou as maiores médias de comprimento, diâmetro e peso da massa fresca (Tab. 2). Uma resposta interessante é que o uso exógeno de macronutrientes em dosagens de 25 a $100 \%$ de N, P e K proporcionou a formação de maior número de frutos por planta (Figura 1), a obtenção de diferentes estádios de desenvolvimento do frutos (E1 a E5) e antecipou o estádio de maturação (E4).

Esse tipo de resposta é importante uma vez que pode ser adotada para o manejo da cultura, e torna-se um recurso importante para o agricultor em se tratando da colheita e da comercialização de frutos durante boa parte do ano. Resultado inverso foi observado por Thomé \& Osaki (2010), que verificaram uma tendência ao decréscimo do peso do fruto com o aumento da adubação química (100\%, 50\%, uma vez e meia e duas vezes da dose recomendada para a cultura do tomate) durante o cultivo de $P$. angulata, cuja espécie apresenta facilidade de cultivo, importância fotoquímica e frutos com potencial econômico. Avaliando o custo benefício do fornecimento de macronutrientes, a adubação exógena pode ser vantajosa para o agricultor em função dos maiores medidas dos frutos e precocidade da colheita de frutos maduros.

Tabela 2. Comprimento, diâmetro e massa fresca dos frutos em diferentes estádios de maturação de Physalis angulata submetidas à diferentes dosagens de N, P e K.

\begin{tabular}{|c|c|c|c|c|c|}
\hline & E1 & E2 & $\mathbf{E 3}$ & E4 & E5 \\
\hline Tratamentos & & & $\mathrm{C}(\mathrm{mm})$ & & \\
\hline 1 & 7,5 & - & - & - & $10,8 *$ \\
\hline 2 & 8,6 & 9,7 & 11,2 & $13,7 *$ & 12,0 \\
\hline 3 & 8,9 & 10,5 & 12,6 & $13,2 *$ & 12,5 \\
\hline \multirow[t]{2}{*}{4} & 8,6 & $11^{\#}$ & 13,1 & $14,3 *$ & $12,9 * \#$ \\
\hline & & & $\mathrm{D}(\mathrm{mm})$ & & \\
\hline 1 & 6,8 & - & - & - & $10,2^{*}$ \\
\hline 2 & 7,2 & 8,7 & 10,5 & $12,6^{*}$ & 11,7 \\
\hline 3 & 7,7 & 9,4 & 11,6 & $13,6 *$ & $12,1 * \#$ \\
\hline \multirow[t]{2}{*}{4} & 7,4 & 9,8 & $12,3^{\#}$ & $14^{*}$ & $12,4 * \#$ \\
\hline & & & MF (g) & & \\
\hline 1 & 0,3 & - & - & - & $0,8^{*}$ \\
\hline 2 & 0,3 & 0,6 & 1,0 & $2,0 *$ & 1,3 \\
\hline 3 & 0,4 & 0,7 & 1,2 & $1,6^{*}$ & 1,3 \\
\hline 4 & 0,4 & 0,8 & 1,4 & $1,9 *$ & $1,4^{\#}$ \\
\hline
\end{tabular}

\# referente aos tratamentos de adubação e * referente aos estádios de maturação, significativos pelo teste Tukey, 5\% de probabilidade. Nota: - frutos insuficientes para a análise. Tratamentos: $1=$ Controle; $2=25 \% ; 3=50 \%$ e $4=100 \%$ da adubação recomendada. Estádios de maturação: E1; E2; E3; E4 e E5.

Sabe-se que o aspecto nutricional da planta-mãe é de grande relevância durante o desenvolvimento da semente, entretanto, nesse trabalho não houve interação significativa entre as variáveis testadas (dosagens de $\mathrm{N}, \mathrm{P}$ e K e o peso das sementes nos diferentes estádios de maturação). Por sua vez, observou-se que o incremento do peso seco das sementes $(\mathrm{mg})$ segue linearmente para todos os estádios de maturação, sendo 
dependente não só dos fatores exógenos (nutricionais) mas também da capacidade de deposição das reservas (fatores endógenos e fisiológicos). Dentro do esperado, os maiores pesos das sementes foram verificados para aquelas oriundas do estádio mais avançados de maturação dos frutos (E5). Nos estádios E1 a E4 houve tendência das sementes serem mais pesadas com o aumento da dosagem de N, P, e K para as plantas.

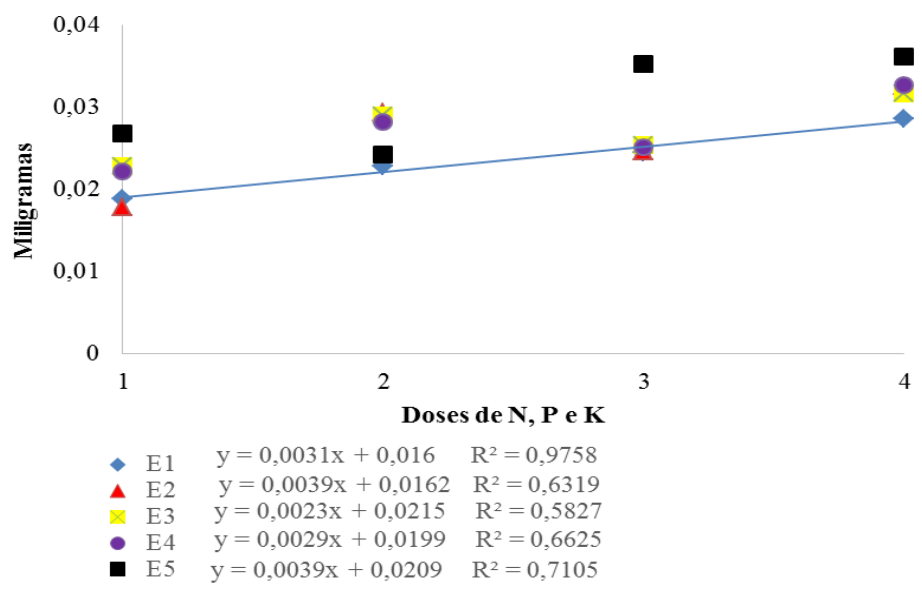

Figura 2. Peso de sementes de Physalis angulata em diferentes estádios de desenvolvimento em provenientes de cultivo com diferentes dosagens de N, P e K. Nota: Estádios de maturação: E1; E2; E3; E4 e E5.

Fica evidente que a variabilidade da média do peso das sementes durante os estádios de maturação foi influenciada pela amostragem e que a classificação e a separação dos frutos nos estádios E1 - E5, baseado somente na coloração do tegumento externo, não é suficiente para determinar com exatidão o ponto de maturidade fisiológica das sementes.

\section{CONSIDERAÇÕES FINAIS}

O cultivo de Physalis angulata é favorecido pela adubação química através das características de crescimento da planta e físicas dos frutos. Em sementes, não foi possível determinar com exatidão a influência sobre a maturidade fisiológica das sementes

\section{REFERÊNCIAS}

CRUZ, J. L. et al. Influência da adubação fosfatada sobre o crescimento do camapu (Physalis angulata L.). Revista Brasileira de Plantas Medicinais, v. 17, n. 3, p. 360-366, 2015.

THOMÉ, M., OSAKI, F. Adubação de nitrogênio, fósforo e potássio no rendimento de Physalis spp. Revista Acad., Ciênc. Agrár. Ambient., v. 8, n. 1, p. 11-18, 2010.

LEITE et al. Hydroponic cultivation of Physalis angulata L.: growth and production under nitrogen doses. Pesquisa Agropecuária Tropical, v. 47, n. 2, p. 145-151, 2017.

LIMA, C. S. M. et al. Crescimento de plantas de Physalis submetidas a diferentes adubações. In: XVIII CIC, XI ENPOS, I mostra científica. Anais... 2009b. 5 p 